\title{
Epifitismo vascular em sítios de borda e interior em Floresta Estacional Semidecidual no Sudeste do Brasil
}

\author{
Fernando Antonio Bataghin ${ }^{1,3}$, José Salatiel Rodrigues Pires ${ }^{1}$ e Fábio de Barros ${ }^{2}$
}

Recebido: 4.10.2011; aceito: 23.05.2012

\begin{abstract}
Vascular epiphytes at the edge and interior of a Semideciduous Forest in Southeastern Brazil). Epiphytes have a key role as environmental indicators and may reflect the degree of local preservation. This research was performed at the Ipanema National Forest, São Paulo State, Brazil, and aimed to characterize the vascular epiphytic community, taking into consideration its abundance and distribution at forest-interior and edge site. In the survey, 16 species belonging to 12 genera in six families were found. Characteristic holoepiphytes were the dominant type of epiphytes. At the forest edge, seven epiphytic species were found, with $\mathrm{H}^{\prime}=1.282$ and $\mathrm{J}=0.658$. At the inner forest site, 13 species were sampled, with $\mathrm{H}^{\prime}=1.587$ and $\mathrm{J}=0.619$. The results indicated that the low diversity of the area may be related to forest disturbance and vegetation types studied, and an edge effect was noted in the vascular epiphytes, both at forest edge and forest-interior sites, leading to changes in species composition and vertical distribution of the community.
\end{abstract}

Key words: Atlantic Forest, edge effect, human action, phytosociology

RESUMO - (Epifitismo vascular em sítios de borda e interior em Floresta Estacional Semidecidual no Sudeste do Brasil). As epífitas têm papel fundamental como indicadores ambientais e podem refletir o grau de preservação local. Esta pesquisa foi desenvolvida na Floresta Nacional de Ipanema, São Paulo, Brasil e objetivou caracterizar a comunidade epifítica vascular, analisando sua abundância e distribuição nos sítios de borda e de interior da floresta. Foram encontradas 16 espécies, pertencentes a 12 gêneros e seis famílias. Houve predominância dos holoepífitos característicos. Na borda foram amostradas sete espécies, com diversidade de Shannon de $\mathrm{H}^{\prime}=1,282$ e equabilidade de Pielou de $\mathrm{J}=0,658$. No interior foram amostradas 13 espécies, com diversidade de Shannon de $\mathrm{H}^{\prime}=1,587$ e equabilidade de Pielou de $\mathrm{J}=0,619$. Os resultados indicaram que a baixa diversidade da área pode estar relacionada a perturbação da floresta e a fitofisionomia pesquisada, e que há ação do efeito de borda sobre as epifíticas vasculares da borda e do interior da floresta, alterando a composição específica e a distribuição vertical da comunidade.

Palavras-chave: Ação antrópica, efeito de borda, fitossociologia, Mata Atlântica

\section{Introdução}

A fragmentação de habitats tem se tornado um dos mais fortes agentes de perda de espécies (Diamond 1992). O efeito direto da fragmentação de habitats é a redução drástica no tamanho efetivo das populações de muitas espécies, resultando muitas vezes em perdas determinísticas, quando populações são reduzidas abaixo do limite de viabilidade genética (Terborgh 1992).

Dentre as consequências mais importantes do processo de fragmentação florestal, pode-se citar a diminuição da diversidade biológica, o distúrbio do regime hidrológico das bacias hidrográficas, as mudanças climáticas, a degradação geral dos recursos naturais e a deterioração da qualidade de vida das populações tradicionais (Pires 1995). Outra consequência é a criação de bordas florestais, que levam a modificações nas condições microclimáticas de parte do fragmento florestal (Williams-Linera 1990, Camargo \& Kapos 1995).

As mudanças na parte física do ambiente, causadas pela borda, podem afetar diretamente a estrutura da floresta (Teixera 1998), causando alterações na

1. Universidade Federal de São Carlos, Centro de Ciências Biológicas e da Saúde, Departamento de Hidrobiologia, Via Washington Luiz, km 235, Monjolinho, 13565-905 São Carlos, SP, Brasil

2. Instituto de Botânica, Núcleo de Pesquisa Orquidário do Estado, Caixa Postal 68041, 04045-972 São Paulo, SP, Brasil

3. Autor para correspondência: bataghin@ufscar.br 
abundância relativa e na composição de espécies de plantas, dado o aumento no recrutamento e densidade de espécies arbóreas pioneiras (Williams-Linera 1990, Laurance et al. 1998, Sizer \& Tanner 1999), o aumento na densidade de cipós (Laurance et al. 2001) e a diminuição na densidade de plântulas de espécies tardias (Benitez-Malvido 1998). Além disso, tais mudanças podem restringir as espécies tolerantes a sombra ao interior dos fragmentos florestais, com espécies distintas estabelecendo-se a distâncias diferentes da borda (Lovejoy et al. 1986). Essas alterações significativas nas características do fragmento florestal compõem o chamado efeito de borda (Saunders et al. 1991).

As epífitas, que representam cerca de $10 \%$ de todas as plantas vasculares (Gentry \& Dodson 1987), se estabelecem diretamente sobre o tronco, ramos caulinares ou sobre as folhas das árvores, sem a emissão de estruturas haustoriais, e as plantas que as sustentam são denominadas forófitos (Benzing 1990). Em função de suas características fisiológicas e nutricionais, as epífitas podem refletir o grau de preservação local e têm um papel fundamental em estudos sobre a interferência antrópica no ambiente (Sota 1971, Aguiar et al. 1981, Barthlott et al. 2001, Wolf 2005, Bonnet \& Queiroz 2006, Dettke et al. 2008, Kersten \& Kuniyoshi 2009, Bataghin et al. 2010), funcionando também como indicadores biológicos do estágio sucessional da floresta e refletindo o grau de preservação local (Meira 1997, Barthlott et al. 2001, Wolf 2005, Bataghin et al. 2008).

O efeito de borda é esperado em epífitas vasculares, uma vez que a ocorrência dessas plantas está relacionada diretamente com a intensidade de luz e a umidade, usualmente maior e menor, respectivamente, na borda da floresta (Santos et al. 2010). Embora os estudos de Bernardi \& Budke (2010) não tenham identificado variação na diversidade e estrutura da comunidade epifítica vascular entre a borda e o interior em uma área de transição entre Floresta Estacional Semidecídua e Floresta Ombrófila Mista, Essen \& Renhorn (1998), estudando epífitas não vasculares (liquens), e Bataghin et al. (2008), analisando epífitas vasculares, detectaram a ocorrência de efeito de borda sobre o componente epifítico.

O conhecimento disponível sobre os remanescentes de vegetação, especialmente no Estado de São Paulo, ainda não permite compreender os mecanismos reguladores da biodiversidade nessas áreas, nem entender como as alterações recentes interferiram nos processos de estruturação e funcionamento dessas florestas. Analisar e correlacionar fatores que regem a dinâmica da floresta é fundamental para o entendimento dos mecanismos mantenedores da biodiversidade, pois o desenvolvimento da comunidade é dependente do conjunto geral de fatores e não da ação isolada de cada um deles. O objetivo deste trabalho foi caracterizar a comunidade epifítica vascular que ocorre em sítios de borda e interior na Floresta Nacional de Ipanema, analisando as diferenças na diversidade, abundância, frequência e distribuição vertical das epífitas entre esses ambientes.

\section{Material e métodos}

A Floresta Nacional de Ipanema com 5.179,93 hectares e altitudes variando de 600 a 850 metros (Fávero 2001), está localizada entre as coordenadas $23^{\circ} 21^{\prime}$ a $23^{\circ} 30^{\prime} \mathrm{S}$ e $47^{\circ} 30^{\prime}$ a $47^{\circ} 45^{\prime} \mathrm{W}$ (figura 1 ). O Trópico de Capricórnio passa pela parte sul da área, caracterizando uma zona de transição, de tropical para subtropical. Segundo o sistema de Köeppen, apresenta condições climáticas tipo Cfa ao sul e Cwa ao norte (IBAMA 2007). Segundo Albuquerque (1999), a precipitação média anual de $1.310 \mathrm{~mm}$, tendo janeiro como mês mais chuvoso $(233 \mathrm{~mm})$ e mais quente (temperatura média de $24,2^{\circ} \mathrm{C}$ ), agosto como mês mais seco $(33 \mathrm{~mm})$ e julho o mês mais frio (temperatura de até $\left.1,4^{\circ} \mathrm{C}\right)$.

A Unidade de Conservação foi criada para preservar um dos maiores fragmentos de Mata Atlântica do interior do Estado de São Paulo, bem como outros ecossistemas associados (áreas de cerrado e várzea), e sua diversidade biológica (IBAMA 2007). No contexto da paisagem regional, a Floresta Nacional de Ipanema é uma área natural extensa de Floresta Estacional Semidecidual, remanescente de uma vegetação hoje totalmente fragmentada.

Albuquerque (1999), em estudo fitossociológico no Morro de Araçoiaba, dentro da Floresta Nacional de Ipanema, encontrou, além de espécies características de Floresta Estacional Semidecidual, espécies pertencentes a formações de Floresta Ombrófila Mista, Cerrado lato sensu e Floresta Ombrófila Densa, e afirmou que a Unidade de Conservação possui uma condição ecotonal na qual a matriz seria Floresta Estacional Semidecidual com exemplares de florestas Ombrófila Densa e Mista, e de Cerrado lato sensu.

O histórico da influência antrópica e dos conflitos ambientais da atual Flona de Ipanema não é recente, ao contrário, remonta à época imediatamente posterior 
ao descobrimento do Brasil. Os primeiros registros datam de 1589, quando os bandeirantes chegaram à área iniciando a extração de minério de ferro. Em 1810, Dom João VI decretou a criação da Fábrica de Ferro Ipanema, a primeira siderúrgica brasileira que se manteve ativa na Flona de Ipanema até 1895. $\mathrm{Na}$ região mais montanhosa da Flona, denominada Serra de Araçoiaba, iniciou-se em 1926 a extração de apatita para fabricação de superfosfato e em 1950 deu-se início à extração de calcário para produção de cimento. Nesta última ocasião, a Flona encontrava-se sob administração do Ministério da Agricultura, que realizava ensaios com sementes e com máquinas agrícolas. Em 1986 a Marinha do Brasil instalou em uma área da Flona, um centro de pesquisas para desenvolver reatores nucleares para submarinos (ARAMAR), um complexo que ocupa 78 ha da área (IBAMA 2003).

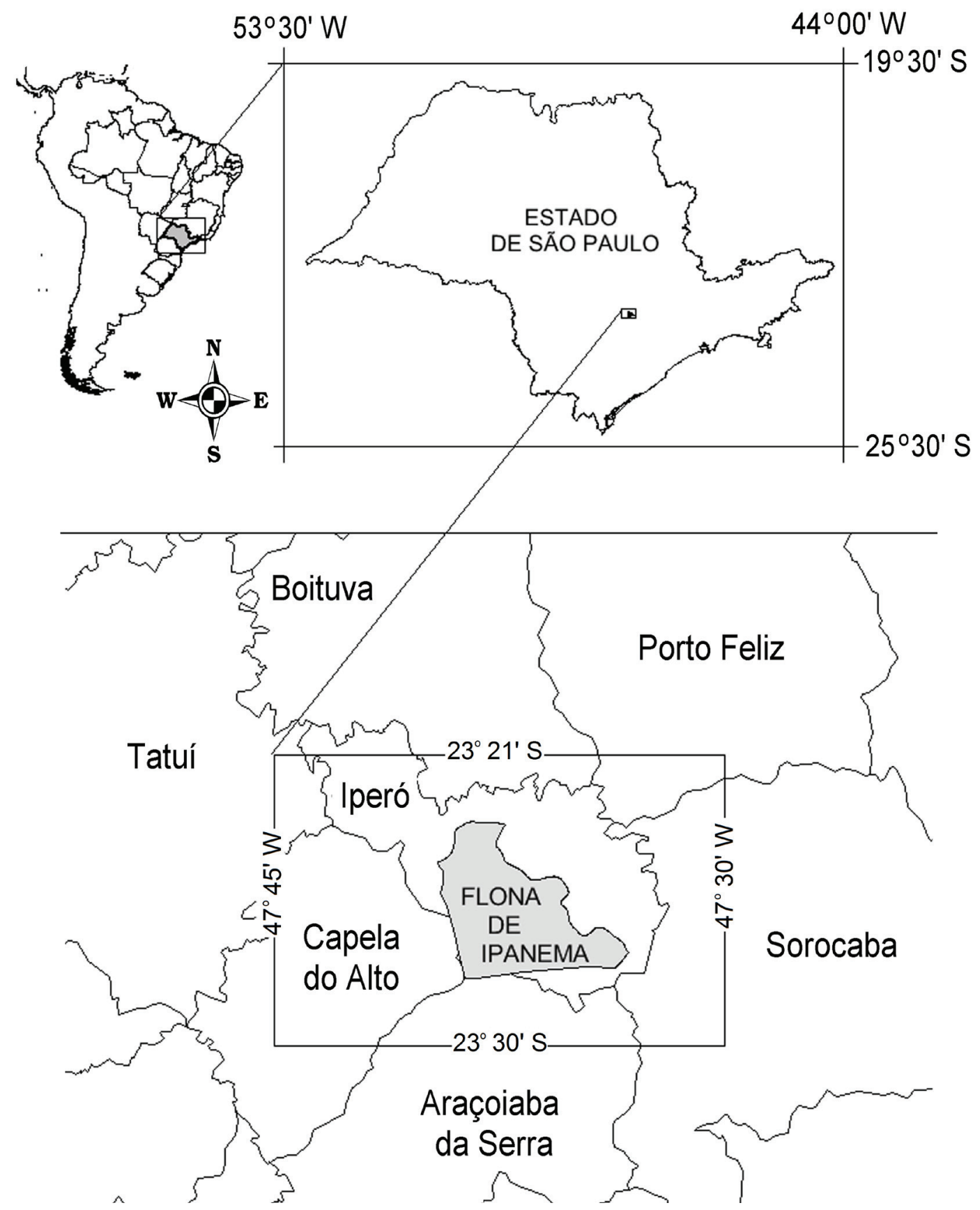

Figura 1. Localização da Floresta Nacional de Ipanema, Estado de São Paulo, Brasil.

Figure 1. Location of the Ipanema National Forest, São Paulo State, Brazil. 
Foram realizadas visitas entre setembro de 2007 e agosto de 2008 amostrando as epífitas vasculares que se encontravam sobre 180 indivíduos arbóreos (forófitos) com DAP $\geq 20 \mathrm{~cm}$ em um sítio de borda e um sítio de interior de floresta. Para cada sítio foram demarcadas parcelas de $10 \times 15 \mathrm{~m}$ até serem amostrados 90 forófitos. $\mathrm{O}$ sítio de borda foi instalado entre 15 e 60 metros da borda (três parcelas), seguindo a amostragem em paralelo a borda externa. $\mathrm{O}$ sítio de interior foi estabelecido entre 300 e 345 metros da borda externa e obedeceu a mesma orientação do sítio de borda.

O material botânico coletado foi processado segundo as técnicas usuais de herborização e depositado no herbário da UFSCar - Campus Sorocaba. A identificação foi feita com base em bibliografia especializada, por comparação com material previamente identificado e consulta a especialistas, sendo adotadas as abreviaturas dos autores sugeridas por Brummitt \& Powell (1992).

As espécies epifíticas foram classificadas em categorias ecológicas, segundo sua relação com o forófito, seguindo Benzing (1990) e Kersten \& Silva (2001), a saber, holoepífitos característicos, holoepífitos facultativos e holoepífitos acidentais. Em adição, foi registrado, para cada espécie, seu posicionamento no forófito (estratos) segundo as categorias sugeridas por Kersten \& Silva (2002): 1 - fuste baixo (até 1,3 m de altura); 2 - fuste alto (de $1,31 \mathrm{~m}$ até a base da copa); 3 - copa.

Foram calculadas as frequências absolutas de ocorrência nos estratos (FAr) e nos indivíduos forofíticos (FAi). O valor de importância epifítico (VIE) foi calculado com base nas notas atribuídas às epífitas, a saber: 1 - um ou poucos indivíduos isolados; 2 - agrupamentos mais extensos ou diversos indivíduos isolados; 3 - abundante e formando, em muitos casos, uma cobertura quase contínua no forófito. Para cálculo do VIE foi empregada a fórmula sugerida por Waechter (1998) e modificada por Kersten \& Silva (2001): $\mathrm{VIE}=\left[\mathrm{vt}\left(\sum \mathrm{vt}\right)^{-1}\right] 100$, onde $\mathrm{vt}=$ somatória das notas obtidas pela espécie e utilizadas as seguintes abreviações: $\mathrm{Ne}$ - número de estratos com ocorrência da espécie epifítica; $\mathrm{Na}$ - número total de regiões amostradas; $\mathrm{Nf}$ - número de indivíduos forofíticos com ocorrência da espécie; $\mathrm{Nt}$ - número total de indivíduos forofíticos.

Foram estimados os parâmetros de diversidade, equabilidade e riqueza, utilizando os índices de diversidade de Shannon $\left(\mathrm{H}^{\prime}\right)$, equabilidade de Pielou (J) e riqueza de Margalef (d). Para explorar a similaridade entre os diferentes sítios e estratos na área de estudo, com base nos táxons identificados, utilizou-se uma análise de agrupamentos, com o método UPGMA, utilizando como medida de distância o coeficiente de similaridade de Jaccard (Odum 1988). Foram aplicados os testes $t$ e Kolmogorov-Smirnov (Magurran 1988) sobre a abundância das espécies epifíticas, para avaliar as possíveis diferenças entre os sítios estudados. A análise da distribuição vertical das epífitas foi realizada de forma a comparar as abundâncias dos estratos da borda em relação ao mesmo estrato no interior da floresta. Foi elaborado um diagrama de Whittaker com os valores de importância epifítica $(\log 10)$ para ilustrar a distribuição vertical da abundância entre as espécies nos sítios estudados. Para realização das análises estatísticas foram utilizados os programas computacionais PAST versão 2.0 (Hammer et al. 2001) e MVSP versão 5.0 (Ayres et al. 2007).

\section{Resultados}

No levantamento florístico dos sítios de borda e interior da Floresta Nacional (Flona) de Ipanema, foram registradas 16 espécies epifíticas, pertencentes a 12 gêneros e seis famílias (tabela 1). As famílias epifíticas com maior riqueza de espécies foram Cactaceae (cinco espécies) e Bromeliaceae (quatro). Polypodiaceae e Orchidaceae apresentaram três e duas espécies, respectivamente. As famílias Araceae e Commelinaceae apresentaram apenas uma espécie.

Com exceção de Oeceoclades maculata, que foi registrada somente no fuste alto, todas as demais espécies epifíticas ocorreram no estrato denominado fuste baixo, sendo que Aechmea bromeliifolia e Tradescantia fluminensis ocorreram exclusivamente nesse estrato. Anthurium comtum e Epidendrum sp. foram registradas nos fustes baixo e alto. As outras espécies ocorreram nos três estrados analisados.

A distribuição das espécies epifíticas, segundo as categorias ecológicas de relação com o forófito, evidenciou o predomínio de holoepífitos característicos com 12 espécies (75\%); os holoepífitos acidentais foram representados por três espécies $(19 \%)$ e os holoepífitos facultativos, por uma espécie $(6 \%)$.

No sítio de borda foram amostradas sete espécies, pertencentes a cinco gêneros e três famílias. Bromeliaceae foi a família de maior riqueza na borda, com quatro espécies, seguida por Polypodiaceae (duas) e Commelinaceae (uma espécie). Na borda predominaram os holoepífitos característicos com seis espécies, sendo registrada uma espécie como 
holoepífito acidental e nenhuma como holoepífito facultativo. As espécies epifíticas com maior valor de importância foram Tillandsia recurvata e Tillandsia tricholepis (tabela 1).

No interior da floresta foram identificadas 13 espécies, pertencentes a 10 gêneros e cinco famílias. As famílias de maior riqueza nesse sítio foram Cactaceae (cinco espécies) e Polypodiaceae (três), seguidas por Bromeliaceae e Orchidaceae, com duas espécies cada e Araceae, com apenas uma espécie. Nesse sítio houve predominância dos holoepífitos característicos (10 espécies), seguidos pelos holoepífitos acidentais (duas) e holoepífitos facultativos, com uma espécie.
Pleopeltis pleopeltifolia obteve o maior valor de importância epifitico (tabela 1), seguida por Rhipsalis cereuscula.

No sítio de borda o índice de Shannon foi $\mathrm{H}^{\prime}=1,282$, a equabilidade de Pielou foi de $\mathrm{J}=0,658$ e a riqueza de Margalef (d) foi de 1,017. Para o sítio de interior, o índice de diversidade de Shannon foi de $H^{\prime}=1,587$, a equabilidade foi de $J=0,619$ e a riqueza (d) foi de 1,919. A diversidade variou de forma significativa entre a borda e o interior $(p<0,001)$, segundo o teste $t$. A diversidade da borda e interior foi menor do em pesquisas realizadas em fitofisionomias semelhantes (tabela 2).

Tabela 1. Espécies epifíticas amostradas nos sítios de Borda e Interior da Flona de Ipanema, SP, Brasil. Abr.: abreviatura. CE: Categoria Ecológica (C: holoepífito característico, F: holoepífito facultativo, A: holoepífito acidental). Pf: Posição no forófito (1: fuste baixo, 2: fuste alto, 3: copa). Ne: número absoluto de ocorrências nos estratos. Nf: número absoluto de ocorrências nos indivíduos forofíticos. VT: estimativas de abundância. VIE: valor de importância epifítico; b: borda; i: interior.

Table 1. Vascular epiphytes sampled at the edge and inside the forest, Ipanema National Forest, São Paulo State, Brazil. Abr.: abbreviation. CE: Ecological categories (C: characteristic holoepiphyte, F: facultative holoepiphyte, A: accidental holoepiphyte). Pf: position in the phorophytes (1: low trunk, 2: high trunk, 3: canopy). Ne: absolute number of occurrences in strata. Nf: absolute events in host trees. VT: abundance estimates. VIE: epiphytic importance value; b: edge; i: inside the forest.

\begin{tabular}{|c|c|c|c|c|c|c|c|c|c|c|c|}
\hline Espécies & Abr. & $\mathrm{CE}$ & $\mathrm{Pf}$ & $\mathrm{Ne} b$ & $\mathrm{Nfb}$ & VT b & $\mathrm{Ne} i$ & $\mathrm{Nf} i$ & VT i & VIE b & VIE i \\
\hline \multicolumn{12}{|l|}{$\overline{\text { ARACEAE }}$} \\
\hline Anthurium comtum Schott & Ac & $\mathrm{F}$ & $1 ; 2$ & - & - & - & 2 & 2 & 3 & - & 0,6 \\
\hline \multicolumn{12}{|l|}{ BROMELIACEAE } \\
\hline Aechmea bromeliifolia (Rudge) Baker & $\mathrm{Ab}$ & $\mathrm{C}$ & 1 & 1 & 1 & 2 & - & - & - & 0,5 & - \\
\hline Tillandsia recurvata $(\mathrm{L}.) \mathrm{L}$. & $\operatorname{Tr}$ & $\mathrm{C}$ & $1 ; 2 ; 3$ & 86 & 58 & 157 & 7 & 6 & 10 & 43,0 & 1,9 \\
\hline Tillandsia stricta Sol. & Ts & $\mathrm{C}$ & $1 ; 2 ; 3$ & 7 & 6 & 7 & - & - & - & 1,9 & - \\
\hline Tillandsia tricholepis Baker & $\mathrm{Tt}$ & $\mathrm{C}$ & $1 ; 2 ; 3$ & 90 & 40 & 128 & 13 & 12 & 17 & 35,1 & 3,3 \\
\hline \multicolumn{12}{|l|}{ CACTACEAE } \\
\hline Cereus alacriportanus Pfeiff. & $\mathrm{Ca}$ & A & $1 ; 2 ; 3$ & - & - & - & 1 & 1 & 1 & - & 0,2 \\
\hline Epiphyllum phyllanthus (L.) Haw. & Ep & $\mathrm{C}$ & $1 ; 2 ; 3$ & - & - & - & 7 & 6 & 13 & - & 2,5 \\
\hline \multirow{3}{*}{$\begin{array}{l}\text { Lepismium cruciforme (Vell.) Miq. } \\
\text { Lepismium warmingianum (K.Schum.) } \\
\text { Barthlott } \\
\text { Rhipsalis cereuscula Haw. }\end{array}$} & Lc & $\mathrm{C}$ & $1 ; 2 ; 3$ & - & - & - & 6 & 4 & 13 & - & 2,5 \\
\hline & Lw & $\mathrm{C}$ & $1 ; 2 ; 3$ & - & - & - & 9 & 6 & 21 & - & 4,0 \\
\hline & $\mathrm{Rc}$ & $\mathrm{C}$ & $1 ; 2 ; 3$ & - & - & - & 78 & 50 & 184 & - & 35,5 \\
\hline \multicolumn{12}{|l|}{ COMMELINACEAE } \\
\hline Tradescantia fluminensis Vell. & $\mathrm{Tf}$ & A & 1 & 2 & 2 & 4 & - & - & - & 1,1 & - \\
\hline \multicolumn{12}{|l|}{ ORCHIDACEAE } \\
\hline Epidendrum sp. & Es & $\mathrm{C}$ & $1 ; 2$ & - & - & - & 2 & 2 & 2 & - & 0,4 \\
\hline Oeceoclades maculata (Lindl.) Lindl. & Om & $\mathrm{C}$ & 2 & - & - & - & 1 & 1 & 2 & - & 0,4 \\
\hline \multicolumn{12}{|l|}{ POLYPODIACEAE } \\
\hline Microgramma squamulosa (Kaulf.) de la Sota & Ms & $\mathrm{C}$ & $1 ; 2 ; 3$ & 6 & 5 & 12 & 15 & 9 & 31 & 3,3 & 6,0 \\
\hline Pleopeltis pleopeltifolia (Raddi) Alston & $\mathrm{Pp}$ & $\mathrm{C}$ & $1 ; 2 ; 3$ & 38 & 31 & 55 & 97 & 57 & 208 & 15,1 & 40,1 \\
\hline Pleopeltis squalida (Vell.) de la Sota & Ps & $\mathrm{C}$ & $1 ; 2 ; 3$ & - & - & - & 6 & 4 & 14 & - & 2,7 \\
\hline
\end{tabular}


Os testes de Kolmogorov-Smirnov e teste $t$ (Student), aplicados a abundância das espécies, não evidenciaram diferença significativa entre a borda e o interior $(p>0,05)$. No entanto, a análise da similaridade de Jaccard entre esses ambientes, com base na distribuição das epífitas vasculares nos estratos (figura 2), apresentou o sítio de borda em um grupo distinto do sítio de interior.

A distribuição das abundâncias das epífitas vasculares nos estratos revelou a dominância de espécies distintas nos ambientes de borda e interior da floresta (figura 3), apesar das comparações estatísticas aplicadas (Kolmogorov-Smirnov e test $t$ ) entre os mesmos estratos na borda e interior, terem revelado apenas o fuste alto como distinto entre esses ambientes $(p<0,001)$. O fuste alto do sítio de interior foi significativamente diferentes $(p<0,005)$ do fuste baixo e da copa nesse mesmo sítio. As espécies Tillandsia recurvata $(\mathrm{Tr})$ e Tillandsia tricholepis $(\mathrm{Tt})$ foram as mais abundantes no fuste alto e na copa no sítio de borda e apresentaram-se entre as mais abundantes no fuste baixo desse mesmo sítio, no entanto, para o sítio de interior essas duas espécies apresentaram-se pouco expressivas, sobretudo no fuste baixo e no fuste alto. No sítio de interior, Rhipsalis cereuscula (Rc) foi a espécie mais abundante no fuste baixo e no fuste alto, e a segunda mais abundante na copa, entretanto essa espécie não foi registrada no sítio de borda. A espécie Pleopeltis pleopeltifolia $(\mathrm{Pp})$, registrada em ambos os sítios, tende a ser, no sítio de borda, mais abundante nos estratos inferiores, notadamente no fuste baixo, enquanto no interior foi mais abundante na copa e no fuste alto.

\section{Discussão}

A riqueza específica observada na área de estudo (tabela 1), pode ser considerada baixa quando comparada com outras áreas que têm o mesmo tipo formação florestal (Floresta Estacional Semidecidual). Os resultados obtidos mostram números menores que os dos estudos realizados por Dislich \& Mantovani (1998) - 34 espécies, Borgo et al. (2002) - 32 espécies, Rogalski \& Zanin (2003) - 70 espécies e por Giongo \& Waechter (2004) - 57 espécies. No entanto, assemelham-se aos dos estudos realizados por Aguiar et al. (1981), que amostraram 17 espécies, com Breier (2005) - 25 espécies e Bernardi \& Budke (2010) - 22 espécies. Pode-se notar, também, semelhança com os estudos de Waechter (1992), que amostrou 24 espécies epifíticas em restinga no Taim-RS; de Piliackas et al. (2000), que encontraram 26 espécies em um manguezal em Ubatuba-SP; e de Bataghin et al. (2008), que amostraram 18 espécies em uma Floresta Ombrófila Mista no norte do Rio Grande do Sul.

Todas as famílias encontradas na área estudada estão entre as mais abundantes mundialmente em termos de quantidade de epífitas (Benzing 1990), exceto a família Commelinaceae, que não é tradicionalmente encontrada como epífita no Brasil. A família Orchidaceae, mesmo sendo a mais rica em epífitas mundialmente (Benzing 1990), sobretudo no Neotrópico (Gentry \& Dodson 1987, Kersten 2006), apresentou apenas duas espécies e um número baixo de ocorrências na área de estudo e ainda assim, uma dessas espécies, Oeceoclades maculata, é tradicionalmente terrícola. A alta intensidade luminosa pode reduzir o crescimento e o desenvolvimento de orquídeas

Tabela 2. Riqueza e diversidade de epífitas vasculares em estudos realizados em Floresta Estacional Semidecidual no Brasil. Nf: número de forófitos; F: número de famílias; Ne: número de espécies; H': índice de Shannon; J: índice de equabilidade de Pielou.

Table 2. Richness and diversity of vascular epiphytes in a number of studies in Semideciduous Seasonal Forest. Nf: number of host trees; F: number of epiphytic families; Ne: number of epiphytic species; H': Shannon index; J: Pielou index.

\begin{tabular}{llrrrrc}
\hline Estudos & Local & Nf & F & Ne & H' & J \\
\hline Giongo \& Waechter (2004) & Eldorado do Sul, RS & 60 & 13 & 50 & 3,343 & 0,87 \\
Dettke et al. (2008) & Maringá, PR & 90 & 8 & 22 & 1,106 & 0,82 \\
Bataghin et al. (2010) & Iperó, SP & 270 & 6 & 21 & 2,172 & 0,71 \\
Bernardi \& Budke (2010) & Erechim, RS, borda & 228 & 7 & 20 & 2,380 & 0,78 \\
Bernardi \& Budke (2010) & Erechim, RS, interior & 271 & 8 & 21 & 2,271 & 0,75 \\
Presente estudo & Iperó, SP, borda & 90 & 3 & 7 & 1,282 & 0,66 \\
Presente estudo & Iperó, SP, interior & 90 & 5 & 13 & 1,587 & 0,62 \\
\hline
\end{tabular}




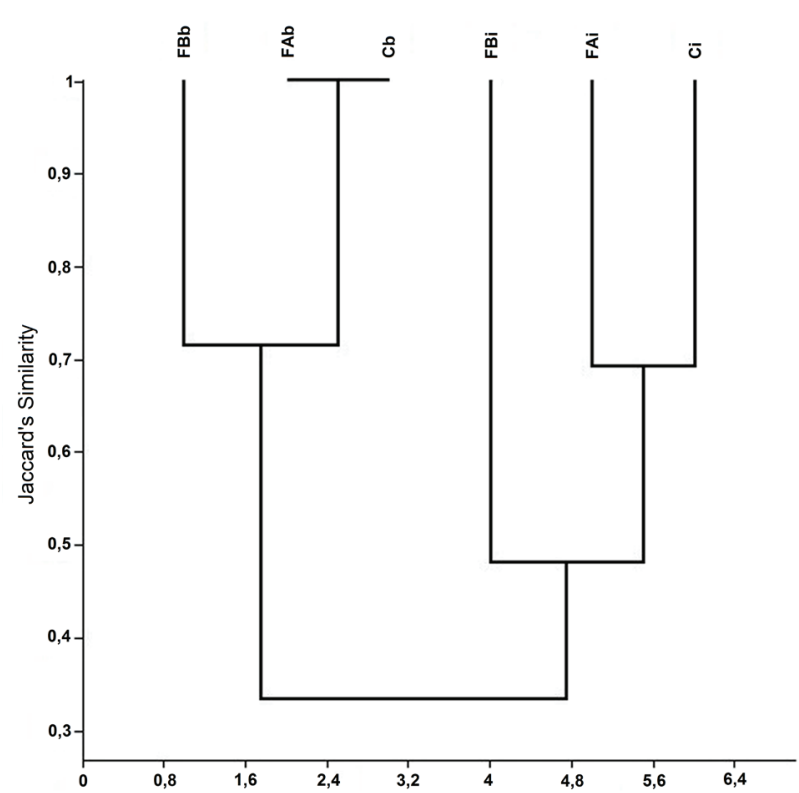

Figura 2: Similaridade florística (índice de Jaccard) entre os estratos nos sítios de borda e interior em Floresta Estacional Semidecidual, Floresta Nacional de Ipanema, SP, Brasil. FB: fuste baixo; FA: fuste alto; C: copa; b: borda; i: interior.

Figure 2: Similarity (Jaccard index) among strata at the edge and inside the forest in a Semideciduous Seasonal Forest, Ipanema National Forest, São Paulo State, Brazil. FB: low trunk; FA: high trunk; C: canopy; B: edge; i: inside the forest.

(Stancato et al. 2002), e o clima seco característico da área de estudo também deve ter influência sobre esses números. Além disso, pesquisas com epífitas em diversas áreas de Floresta Estacional Semidecidual revelaram uma baixa riqueza de orquídeas, como em Dislich \& Mantovani (1998) - 6 spp., Breier (2005) - 3 spp., Dettke et al. (2008) - 3 spp., Bataghin et al. (2010) - 2 spp., Bernardi \& Budke (2010) - 4 spp. O pequeno número de espécies pode representar a riqueza real da família Orchidaceae para remanescentes de Floresta Estacional Semidecidual.

A família Cactaceae, apesar de ser responsável por menos de $0,5 \%$ das espécies epifíticas mundiais (Benzing 1990) e por cerca de 3\% das espécies epifíticas brasileiras (Kersten 2006), foi a mais expressiva na área de estudo, sendo responsável por $31 \%$ das espécies. A grande diversidade de espécies da família Cactaceae na região Neotropical, onde ocorrem mais de 1.400 espécies (Hunt et al. 2006), aliada a resistência dessa família ao estresse hídrico, podem estar relacionadas com a riqueza desta na área estudada.

O predomínio de holoepífitos característicos na área em estudo (tabela 1), também foi observado em
Floresta Estacional Semidecidual por Pinto et al. (1995), Dislich \& Mantovani (1998), Rogalski \& Zanin (2003), Dettke et al. (2008), Bataghin et al. (2010) e Bernardi \& Budke (2010). O mesmo pode ser dito, em relação a outras formações florestais, com base nos trabalhos de Dittrich et al. (1999) em Floresta Ombrófila Mista, e Waechter (1992) e Kersten \& Silva (2001), em áreas de restinga.

A dinâmica de populações de epífitas tem sido pouco considerada em estudos científicos (Kersten 2006, 2010, Bataghin et al. 2010), no entanto sabe-se que a densidade de indivíduos e espécies é inversamente correlacionada ao grau de perturbação ou alteração dos ecossistemas florestais (Bonnet \& Queiroz 2000, Barthlott et al. 2001).

$\mathrm{Na}$ borda, local de ocorrência do chamado efeito de borda, a presença de fatores abióticos, como a maior velocidade de vento, o aumento da luminosidade e da temperatura, e a diminuição da umidade relativa (Murcia 1995), podem ter exercido influência direta na baixa diversidade epifítica. No interior da floresta, a ausência do efeito de borda contribuiu para a maior diversidade do sítio, especialmente pela maior disponibilidade de água (umidade) que é limitante para a comunidade epifítica. $\mathrm{O}$ estresse hídrico é uma das maiores dificuldades para a sobrevivência acima do solo (Laube \& Zotz 2003). Fatores como disponibilidade de nutrientes e irradiação solar, em geral, são menos importantes (Zotz \& Hietz 2001), mas não podem ser excluídos dentre as necessidades das plantas epifíticas.

Os valores de diversidade e equabilidade, tanto dos sítios de borda quanto de interior, podem ser considerados baixos quando comparados a estudos realizados em áreas florestais semelhantes (tabela 2), como nos trabalhos de Giongo \& Waechter (2004) e Bernardi \& Budke (2010), no entanto, apresentam valores de diversidade semelhantes aos observados por Dettke et al. (2008), embora neste a equabilidade tenha sido maior do que no presente estudo. Na Flona de Ipanema a baixa diversidade de espécies epifíticas observada, está relacionada não só a fitofisionomia envolvida, que em vários estudos não apresenta grande diversidade epifítica (tabela 2), mas pode ser um reflexo do longo período de interferências humanas sobre a floresta (IBAMA 2003).

Embora não haja diferença significativa entre as abundâncias das comunidades epifíticas que ocupam a borda e o interior da floresta, o que pode ter ocorrido pelo fato das espécies mais comuns na borda também ocorrerem no interior, embora com menor abundância, 

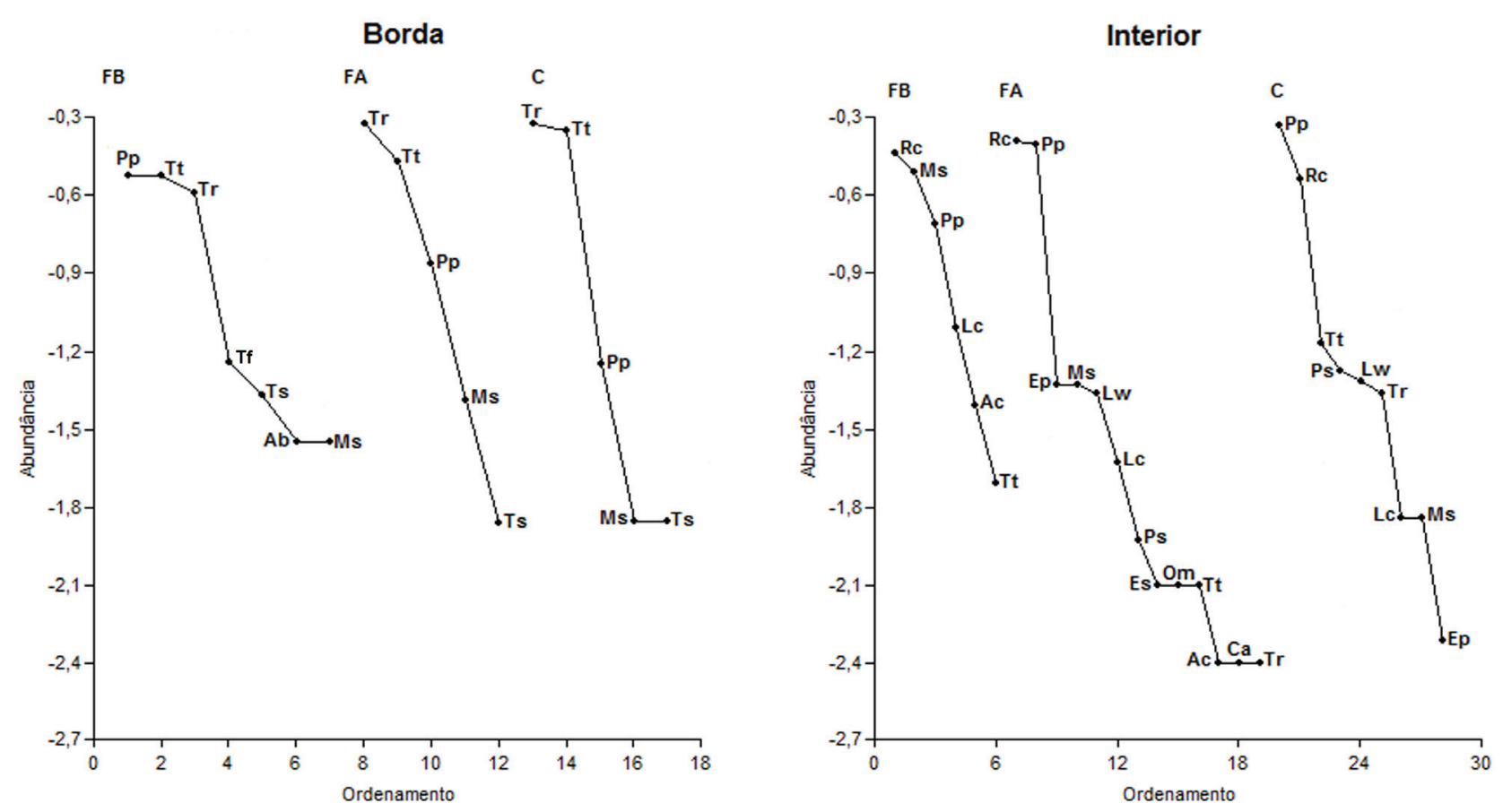

Figura 3. Abundância das epífitas vasculares (Diagrama de Whittaker) nos diferentes estratos em sítios de borda e interior em Floresta Estacional Semidecidual, Floresta Nacional de Ipanema, SP, Brasil. Abreviaturas dos nomes das espécies nas curvas, de acordo com a tabela 1. FB: fuste baixo; FA: fuste alto; C: copa.

Figure 3. Abundance of vascular epiphytes (Whittaker diagram) in different strata at the edge and inside the forest in a Semideciduous Seasonal Forest, Ipanema National Forest, São Paulo State, Brazil. Abbreviation of species' names on the curves according to table 1. FB: low trunk; FA: high trunk; C: canopy.

as análises estatísticas mostraram que a diversidade variou significativamente entre os dois sítios. Em adição, a análise florística entre os estratos na borda e interior revelaram maior similaridade entre os estratos de borda (figura 2), formando um agrupamento distinto dos estratos de interior, indicando a existência de estruturas distintas nas comunidades de epífitas que ocorrem na borda e interior da floresta estudada. Esse fato fornece um indicativo de que fatores abióticos, como a maior luminosidade, velocidade do vento e temperatura, além da menor disponibilidade de umidade exercem influência sobre a comunidade epifítica que ocorre na borda da floresta. Além disso, das espécies registradas no sítio de borda, todas estão presentes no fuste baixo (figura 3). Essa distribuição sugere que, na borda, a chamada "evolução vertical" (Kira \& Yoda 1989, Benzing 1990), não se dá de forma efetiva, pois a luminosidade alcança os estratos inferiores de forma suficiente para a manutenção da comunidade epifítica.

Entre as espécies identificadas no estudo, três ocorrem exclusivamente na borda e nove foram registradas apenas no interior da floresta (tabela 1). Esse fato indica a ação do efeito de borda sobre a comunidade epifítica vascular, limitando a ocorrência de espécies nos ambientes distintos, e mostrando que o efeito de borda tem efeito sobre a distribuição das espécies no ambiente e também na distribuição vertical da sinúsia epifítica. A restrição de espécies tolerantes a sombra ao interior de fragmentos florestais, com espécies distintas se estabelecendo a diferentes distâncias da borda foi apontada por Lovejoy et al. (1986), como uma consequência do efeito de borda. A presença de efeito de borda sobre a comunidade de epífitas vasculares havia sido observada nos estudos de Viero Dias (2005) e Bataghin et al. (2008), ambos em Floresta Ombrófila Mista, e refutada na pesquisa de Bernardi \& Budke (2010), em área com características predominantes de Floresta Estacional Semidecidual.

Ainda no que diz respeito a distribuição vertical das epífitas vasculares, as comparações entre os mesmos estratos na borda e no interior revelou que o fuste alto é significativamente diferente entre os ambientes, bem como dentro do sítio de interior. Krömer et al. (2007), registraram maior diversidade e abundância de espécies nos estratos intermediários em floresta úmida. Entretanto, a distribuição das abundâncias das espécies epifíticas (figura 3) nos estratos apresentou-se distinta entre borda e interior da floresta, corroborando os resultados de Bataghin et al. 
(2008) para epífitas vasculares e de Essen \& Renhorn (1998) para liquens epífiticos. Espécies abundantes na borda, especialmente no fuste alto e na copa - como é o caso de Tillandsia recurvata e T. tricholepis - têm abundância menor nos mesmos estratos no sítio de interior. O mesmo ocorre para espécies dominantes no interior, como é o caso de Rhipsalis cereuscula, que embora abundante no fuste baixo e no fuste alto nesse sítio, não foi registrada na borda da floresta. Variações na distribuição espacial de epífitas foram observadas por Arévalo \& Betancur (2006), que sugerem que as condições de umidade e luminosidade exerceram influência sobre a sinúsia epifítica.

O predomínio de espécies de Tillandsia na borda da floresta, onde as mesmas obtiveram os maiores valores de importância (tabela 1), não é incomum, haja vista que são espécies de ampla distribuição e, frequentemente, observadas em áreas com maior luminosidade ou mesmo em áreas antropizadas (Kersten 2006). Em contrapartida, a restrição das Cactaceae no interior da floresta, não era esperado, embora no estudo realizado por Dettke et al. (2008), essas tenham mostrado preferência por áreas com menor intensidade luminosa.

Apesar das abundâncias das epífitas, entre a borda e o interior da floresta, terem variado apenas para o fuste alto, a maior diversidade epifítica do sítio de interior em relação ao sítio de borda, as diferenças na composição florística e a existência de espécies de ocorrência restritas a ambiente de borda e interior, bem como as diferenças na distribuição vertical das epífitas nesses ambientes, são indicativos da ação dos chamados efeitos de borda sobre a comunidade epifítica vascular na Floresta Estacional Semidecidual na Floresta Nacional de Ipanema.

\section{Agradecimentos}

Os autores agradecem aos pesquisadores Prof. Dr. Jefferson Prado e Ms. Pedro Bond Schwartsburd pela contribuição na identificação das samambaias. Ao Instituto de Botânica de São Paulo. À Floresta Nacional de Ipanema, por permitir a realização desta pesquisa. Ao Laboratório de Análise e Planejamento Ambiental (LAPA) da Universidade Federal de São Carlos, por proporcionar a realização desta pesquisa. A Fundação de Amparo a Pesquisa do Estado de São Paulo - FAPESP (processo 2009/08204-9). Fábio de Barros agradece ao CNPq pela bolsa de produtividade em pesquisa recebida.

\section{Literatura citada}

Aguiar, L.W., Citadine-Zanette, V., Martau, L. \& Backes, A. 1981. Composição florística de epífitos vasculares numa área localizada no município de Montenegro e Triunfo, Rio Grande do Sul, Brasil. Iheringia, série Botânica 28: 55-93.

Albuquerque, G.B. 1999. Floresta Nacional de Ipanema: Caracterização da vegetação em dois trechos distintos do Morro de Araçoiaba, Iperó (SP). Dissertação de Mestrado, Escola Superior de Agricultura "Luiz de Queiroz", Piracicaba.

Arévalo, R. \& Betancur, J. 2006. Vertical distribution of vascular epiphytes in four forest types of the Serranía de Chiribiquete, Colombian Guayana. Selbyana 27: 175-185.

Ayres, M., Ayres Júnior, M., Ayres, D.L. \& Santos, A.A. 2007. BIOESTAT - Aplicações estatísticas nas áreas das ciências bio-médicas, versão 5.0. Ong Mamiraua, Belém.

Barthlott, W., Schmit-Neuerburg, V., Nieder, J. \& Engwald, S. 2001. Diversity and abundance of vascular epiphytes: a comparison of secondary vegetation and primary montane rain forest in the Venezuelan Andes. Plant Ecology 152: 145-156.

Bataghin, F.A., Barros, F. \& Pires, J.S.R. 2010. Distribuição da comunidade de epífitas vasculares em sítios sob diferentes graus de perturbação na Floresta Nacional de Ipanema, São Paulo, Brasil. Revista Brasileira de Botânica 33: 531-542.

Bataghin, F.A., Fiori, A. \& Toppa, R.H. 2008. Efeito de borda sobre epífitas vasculares em Floresta Ombrófila Mista, Rio Grande do Sul, Brasil. O Mundo da Saúde 32: 329-338.

Benitez-Malvido, J. 1998. Impact of forest fragmentation on seedling abundance in a tropical rain forest. Conservation Biology 12: 380-389.

Benzing, D.H. 1990. Vascular epiphytes. Cambridge University Press, Cambridge.

Bernardi, S. \& Budke, J.C. 2010. Estrutura da sinúsia epifítica e efeito de borda em uma área de transição entre Floresta Estacional Semidecídua e Floresta Ombrófila Mista. Floresta 40: 81-92.

Bonnet, A. \& Queiroz, M.H. 2006. Estratificação vertical de bromélias epifíticas em diferentes estádios sucessionais da Floresta Ombrófila Densa, Ilha de Santa Catarina, Santa Catarina, Brasil. Revista Brasileira de Botânica 29: 217-228.

Bonnet, A. \& Queiroz, M.H. 2000. Considerações sobre bromélias epifíticas como indicadores de florestas degradadas. Unidade de Conservação ambiental Desterro, Ilha de Santa Catarina. In: Anais do II Congresso Brasileiro de Unidades de Conservação. v.2. Trabalhos técnicos. Rede Nacional Pró Unidades de Conservação e Fundação o Boticário de Proteção à Natureza, Campo Grande, pp. 217-221. 
Borgo, M., Silva, S.M. \& Petean, M.P. 2002. Epífitos vasculares em um remanescente de floresta estacional semidecidual, município de Fênix, PR, Brasil. Acta Biologica Leopoldensia 24: 121-130.

Breier, T.B. 2005. O epifitismo vascular em florestas do sudoeste do Brasil. Tese de Doutorado, Universidade Estadual de Campinas, Campinas.

Brummitt, R.K. \& Powell, C.E. 1992. Authors of plant names. 1 ed. Royal Botanic Gardens, Kew.

Camargo, J.L.C. \& Kapos, V. 1995. Complex edge effects on soil moisture and microclimate in central Amazonian forest. Journal of Tropical Ecology 11: 205-221.

Dettke, G.A., Orfrini, A.C. \& Milaneze-Gutierre, M.A. 2008. Composição florística e distribuição de epífitas vasculares em um remanescente alterado de Floresta Estacional Semidecidual no Paraná, Brasil. Rodriguésia 59: $859-872$.

Diamond, J. 1992. Overview of recent extinctions. In: D. Westem \& P. Mary (orgs.). Conservation for the twenty-first century. Wildlife Conservation International New York Zoological Society, Oxford University Press, New York, pp. 37-41.

Dislich, R. \& Mantovani, W. 1998. Flora de epífitas vasculares da Reserva da Cidade Universitária "Armando de Salles Oliveira" (São Paulo, Brasil). Boletim de Botânica da Universidade de São Paulo 17: 61-83.

Dittrich, V.A.O., Kozera, C. \& Silva, S.M. 1999. Levantamento florístico de epífitos vasculares no Parque Barigui, Paraná, Brasil. Iheringia, série Botânica 52: 11-22.

Essen, P. \& Renhorn, K. 1998. Edge effects on epiphytic lichen in fragmented forests. Conservation Biology 12: 1307-1317.

Fávero, O.A. 2001. Do berço da siderurgia brasileira à conservação de recursos naturais: um estudo da paisagem da Floresta Nacional de Ipanema (Iperó / SP). Dissertação de Mestrado, Universidade de São Paulo, São Paulo.

Gentry, A.H. \& Dodson, C.H. 1987. Diversity and biogeography of neotropical vascular epiphytes. Annals of the Missouri Botanical Garden 74: 205-233.

Giongo, C. \& Waechter, J.L. 2004. Composição florística e estrutura comunitária de epífitos vasculares em uma floresta de galeria na Depressão Central do Rio Grande do Sul. Revista Brasileira de Botânica 27: 563-572.

Hammer, Ø., Harper, D.A.T. \& Ryan, P.D. 2001. PAST: Paleontological Statistics Software Package for Education and Data Analysis. Palaeontologia Electronica 4 (não paginado).

Hunt, D., Taylor, N. \& Charles, G. 2006, The new cactus lexicon. DH Books, Milborne Port.

IBAMA. 2003. Plano de Manejo: Floresta Nacional de Ipanema, Iperó. Ministério do Meio Ambiente, Brasília.
IBAMA. 2007. Floresta Nacional de Ipanema, Iperó. Superintendência do IBAMA em São Paulo, São Paulo.

Kersten, R.A. \& Kuniyoshi, Y.S. 2009. Conservação das florestas na Bacia do Alto Iguaçu, Paraná - Avaliação da comunidade de epífitas vasculares em diferentes estágios serais. Floresta 39: 51-66.

Kersten, R.A. \& Silva, S.M. 2001. Composição florística e distribuição espacial de epífitas vasculares em floresta da planície litorânea da Ilha do Mel, Paraná, Brasil. Revista Brasileira de Botânica 24: 213-226.

Kersten, R.A. \& Silva, S.M. 2002. Florística e estrutura do componente epifítico vascular em Floresta Ombrófila Mista Aluvial do Rio Barigüi, Paraná, Brasil. Revista Brasileira de Botânica 5: 259-267.

Kersten, R.A. 2006. Epifitismo vascular na bacia do Alto Iguaçu, Paraná. Tese de Doutorado, Universidade Federal do Paraná, Curitiba.

Kersten, R.A. 2010. Epífitas vasculares - Histórico, participação taxonômica e aspectos relevantes, com ênfase na Mata Atlântica. Hoehnea 37: 9-38.

Kira, T. \& Yoda, K. 1989. Vertical stratification in microclimate. In: H. Lieth \& M.J.A. Werger (eds.). Ecosystems of the world. v.14b. Tropical Rain Forest ecosystems. Elsevier, Amsterdam, pp. 7-53.

Krömer, T., Kessler, M. \& Gradstein, R.S. 2007. Vertical stratification of vascular epiphytes in submontane and montane forest of the Bolivian Andes: the importance of the understory. Plant Ecology 189: 261-278.

Laube, S. \& Zotz, G. 2003. Which abiotic factors limit vegetative growth in a vascular epiphyte? Functional Ecology 17: 598-604.

Laurance, W.F., Ferreira, L.V., Rankin-de-Merona, J.M., Laurance, S., Hutchings, R.W. \& Lovejoy, T.E. 1998. Effects of forest fragmentation on recruitment patterns in Amazonian tree communities. Conservation Biology 12: 460-464.

Laurance, W.F., Albernaz, A.K.M. \& Costa, C. 2001. Is deforestation accelerating in the Brazilian Amazon? Environmental Conservation 28: 305-311.

Lovejoy, T.E., Bierregaard, R.O., Rylands, A.B., Malcolm, J.R., Quintela, C.E., Harper, L.H., Brown, K.S., Powell, G.V.N., Schubart, H.O.R. \& Hay, M.B. 1986. Edge and other effects of isolation on Amazon forest fragments. In: M.E. Saule (org.). Conservation biology. Sinauer Press, Massachusetts, pp. 257-285.

Magurran, A.E. 1988. Ecological diversity and its measurement. Princeton University, Princeton.

Meira, M.S. 1997. Distribuição espacial de populações de Bromeliáceas terrestres em um mosaico de floresta e campo. Dissertação de Mestrado, Universidade Federal do Rio Grande do Sul, Porto Alegre.

Murcia, C. 1995. Edge effects in fragmented forests: implications for conservation. Trends in Ecology and Evolution 10: 58-62. 
Odum, E.P. 1988. Ecologia. Guanabara, Rio de Janeiro.

Piliackas, J.M., Barbosa, L.M. \& Catharino, E.L.M. 2000. Levantamento das epífitas vasculares do manguezal do Rio Picinguaba, Ubatuba, São Paulo. In: S. Watanabe (ed.). Anais do $5^{\circ}$ Simpósio de Ecossistemas Brasileiros. Academia de Ciências do Estado de São Paulo, São Paulo, v.2, pp. 357-363.

Pinto, A.C., Demattê, M.E.S.P. \& Pavani, M.C.M.D. 1995. Composição florística de epífitas (Magnoliophyta) em fragmento de floresta no município de Jaboticabal, SP, Brasil. Científica 22: 283-289.

Pires, J.S.R. 1995. Análise ambiental voltada ao planejamento e gerenciamento do ambiente rural: Abordagem metodológica aplicada ao Município de Luiz Antonio - SP. Tese de Doutorado, Universidade Federal de São Carlos, São Carlos.

Rogalski, J.M. \& Zanin, E.M. 2003. Composição florística de epífitos vasculares no estreito de Augusto César, Floresta Estacional Decidual do Alto Uruguai, RS, Brasil. Revista Brasileira de Botânica 26: 551-556.

Santos, A.C.L., Melo, M.M.R.F. \& Eisenlohr, P.V. 2010. Trilhas podem influenciar a composição florística e a diversidade de epífitas na Floresta Atlântica? Hoehnea 37: 743-754.

Saunders, D.A., Hobbs, R.J. \& Margulis, C.R. 1991. Biological consequences of ecosystem fragmentation: a review. Conservation Biology 5: 18-35.

Sizer, N. \& Tanner, E.V.J. 1999. Response of woody plant seedlings to edge formation in a lowland tropical rainforest, Amazonia. Biological Conservation 91: 135-142.
De la Sota, E.R. 1971. El epifitismo y las pteridofitas en Costa Rica (America Central). Nova Hedwigia 21: 401-465.

Stancato, G.C., Mazzafera, P. \& Buckeridge, M.S. 2002. Effects of light stress on the growth of the epiphytic orchid Cattleya forbesii Lindl. $\times$ Laelia tenebrosa Rolfe. Revista Brasileira de Botânica 25: 229-235.

Teixeira, C.V. 1998. Florística e estrutura da borda de um fragmento florestal na cidade de São Paulo. Dissertação de Mestrado, Universidade de São Paulo, São Paulo.

Terborgh, J. 1992. Maintenance of diversity in tropical forests. Biotropica 24: 283-292.

Vieiro-Dias, F. 2005. Estudo fitossociológico de epífitos vasculares no gradiente borda-interior de um remanescente de Floresta Ombrófila Mista. Trabalho de Conclusão de Curso, Universidade Regional Integrada do Alto Uruguai e das Missões, Erechim.

Waechter, J.L. 1992. O epifitismo vascular na planície costeira do Rio Grande do Sul. Tese de Doutorado, Universidade Federal de São Carlos, São Carlos.

Waechter, J.L. 1998. Epifitismo vascular em uma floresta de restinga do Brasil subtropical. Ciência e Natura 20: 43-66.

Willians-Linera, G. 1990. Origin and early development of forest edge vegetation in Panamá. Biotropica 22: $235-241$.

Wolf, J.H.D. 2005. The response of epiphytes to anthropogenic disturbance of pine-oak forests in the highlands of Chiapas, Mexico. Forest Ecology and Management 212: 376-393.

Zotz, G. \& Hietz, P. 2001. The physiological ecology of vascular epiphytes: current knowledge, open questions. Journal of Experimental Botany 52: 2067-2078. 
